\title{
Tuberculose Primária da Mama
}

\author{
Primary Tuberculosis of the Breast
}

\begin{abstract}
Elisvania Rodrigues da Silva, Emmanuel Filizola Cavalcante, Ercio Ferreira Gomes, Francisco Valdeci de Almeida Ferreira, Lázaro Rogério Carvalho Soares, Guilherme Henrique Campos Furtado, Sérgio Ferreira Juaçaba
\end{abstract}

\begin{abstract}
RESUMO
Objetivos: apresentar casuística de tuberculose mamária e a avaliação dos métodos diagnósticos e clínicos para diagnóstico diferencial com carcinoma e sua evolução após tratamento.

Pacientes e Métodos: foram incluidas duas pacientes com tuberculose mamária admitidas e acompanhadas em nosso Serviço de Mastologia e uma paciente da clínica privada no período de março 2001 a março de 2002. Foram avaliados os sintomas e sinais clinicos, achados laboratorias e de imagem, curso clínico, resposta terapêutica e seguimento.

Resultados: a média de idade foi de 40,6 anos. Os sinais e sintomas mais freqüentes foram a dor e tumoração na mama. Em duas pacientes o diagnóstico presuntivo baseou-se nos achados clínicos e histopatológicos (processo inflamatório granulomatoso) e na resposta terapêutica aos tuberculostáticos. O diagnóstico microbiológico foi dado obtido em apenas uma paciente, por meio do achado do bacilo de Koch no tecido mamário. O esquema triplice tuberculostático utilizado foi à base de rifampicina, isoniazida e pirazinamida, obtendo-se regressão das lesões mamárias.

Conclusão: a tuberculose mamária primária é entidade rara que pode se apresentar clinicamente como nódulo mamário e radiologicamente como carcinoma, sendo importante o seu conhecimento para diagnóstico diferencial na presença de massa mamária.
\end{abstract}

PALAVRAS-CHAVE: Mama: infecções. Tuberculose.

\section{Introdução}

Nos últimos anos, associados à AIDS, os casos de tuberculose vêm aumentando em todo mundo, tendo como principal apresentação a forma pulmonar, mas também sendo vistos nas formas extrapulmonares. A incidência da infecção tuberculosa é de cerca de $0,1 \%$ a $0,3 \%$, sendo que na década passada foi notificada média anual mundial de 2,5 milhões de casos, ocorrendo principalmente em países da África, Ásia e América do Sul ${ }^{1}$. Apesar disso, continuam incomuns os relatos de tuberculose mamária, desde a sua descrição inicial por Sir Astley Cooper em 1829, que a ela se referiu como "scrofulous swelling of the bosom", havendo menos de 1000 casos descritos

Hospital do Câncer do Ceará - Instituto do Câncer do Ceará Correspondência:

Elisvania Rodrigues da Silva

Rua Professor Heráclito, 440 apt $^{\circ} 401$ - Papicu

60175-595 - Fortaleza - CE

e-mail: lazrog@ig.com.br e oncocirurgia@hospcancer-icc.org.br na literatura desde então. Em 1899, Warthin valorizou a relação entre a mastite tuberculosa e câncer de mama ${ }^{1}$. Na forma nodular pode simular um carcinoma e na forma disseminada, sugerir um carcinoma inflamatório. Abboud et al. ${ }^{2}$ publicaram um caso da forma inflamatória difusa da tuberculose mamária, e o diagnóstico diferencial foi feito inicialmente com carcinoma, sendo posteriormente confirmado pela cultura com a identificação do Mycobacterium tuberculosis. A doença acomete quase que exclusivamente o sexo feminino e mais a mulher negra do que a branca. $\mathrm{O}$ exame histopatológico é arma importante de diagnóstico nas formas extrapulmonares de tuberculose e na mama esta se apresenta como granuloma com necrose de caseificação e infiltrado inflamatório histiocitário ${ }^{1}$. O diagnóstico microbiológico é dado pela identificação do bacilo álcool-ácido resistente (BAAR). O'Reilly et al. ${ }^{3}$ relataram um caso de tuberculose mamária em paciente de 84 anos que respondeu ao tratamento empírico com drogas tuberculostáticas, permane- 
cendo assintomática após 2 anos.

Embora a incidência da doença seja pequena, o diagnóstico deve ser suspeitado em mulheres multiparas e jovens com nódulo de mama nas quais a malignidade tenha sido excluída. A minima intervenção cirúrgica (incisão ou biópsia excisional) junto com drogas tuberculostáticas parecem ser o tratamento de melhor sucesso. O objetivo deste trabalho é descrever três casos de tuberculose primária da mama, em pacientes do sexo feminino, sem outros locais de infecção evidente, com ênfase no reconhecimento da apresentação mamária da tuberculose extrapulmonar na ausência de outros focos de infecção e seu diagnóstico diferencial com carcinoma mamário por meio do exame histopatológico e microbiológico. O teste terapêutico, ou seja, o uso de tuberculostático sem a visualização do BAAR, foi aplicado para duas pacientes com adequada resposta clinica. Em apenas uma paciente foi identicado o bacilo de Koch pelo exame microbiológico.

\section{Pacientes e Métodos}

Das pacientes avaliadas, duas foram atendidas no Ambulatório de Mastologia do nosso serviço e uma proveniente da clínica privada, entre março de 2001 a março de 2002. Todas as pacientes foram submetidas a exame clínico, biópsia das lesões com exame histopatológico, radiografia de tó- rax, mamografia, teste do PPD e exame microbiológico e cultura bacteriológica para BAAR. Não foram encontrados outros focos de infecção tuberculosa. As pacientes receberem o mesmo esquema tríplice tuberculostático durante o periodo de 6 meses; em duas a terapêutica foi iniciada empiricamente, pois o bacilo de Koch foi identificado apenas em uma paciente pelo exame microbiológico. O seguimento foi feito durante todo o periodo de tratamento com os tuberculostáticos, por meio de consulta ambulatorial mensal no serviço de Mastologia e Infectologia por um período de 1 ano, sendo as mesmas avaliadas quanto a regressão das lesões ou surgimento de outros sintomas.

\section{Resultados}

Quanto aos dados epidemiológicos, a média da idade das pacientes foi de 40,6 anos; duas das três pacientes são da raça negra e tiveram uma média de 2 filhos.

$\mathrm{Na}$ Tabela 1 mostram-se os resultados dos exames laboratoriais e de imagem realizados para o diagnóstico da tuberculose mamária, e observase que apenas no caso 3 foi encontrado o bacilo de Koch.

Os sinais e sintomas mais frequentes estão expostos na Tabela 2. Nota-se a presença de dor e nódulo em todas as pacientes e em $2 / 3$ estavam presentes as fistulas, hiperemia, drenagem purulenta e adenopatia axilar.

Tabela 1 - Dados laboratoriais e de imagem.

\begin{tabular}{cccccc}
\hline Casos & Rx Tórax & PPD & Bacterioscopia (BAAR) & Cultura (BAAR) & Exame microbiológico \\
\hline 1 & $\mathrm{~N}$ & $\mathrm{NR}$ & - & - & - \\
2 & $\mathrm{~N}$ & $\mathrm{RF}$ & - & - & - \\
3 & $\mathrm{~N}$ & $\mathrm{NR}$ & - & + & + \\
\hline $\mathrm{N}:$ normal; NR: não reator: RF: reator fraco; (+): positivo; (-): negativo; BAAR: bacilo álcool-ácido resistente & &
\end{tabular}

N: normal; NR: não reator; RF: reator fraco; (+): positivo; (-): negativo; BAAR: bacilo álcool-ácido resistente

Tabela 2 - Sinais e sintomas mais freqüentes.

\begin{tabular}{lccc}
\hline Sinais e sintomas & Caso 1 & Caso 2 & Caso 3 \\
\hline Dor & + & + & + \\
Hiperemia & + & + & - \\
Fístulas & + & + & - \\
Nódulo & + & + & + \\
Drenagem purulenta & + & + & - \\
Retração de pele & - & - & + \\
Adenopatia axilar & + & + & - \\
Ulceração & - & + & - \\
\hline
\end{tabular}

(+): positivo; (-): negativo
Os dados mais detalhados de cada paciente estão descritos abaixo:

Caso 1 - Paciente do sexo feminino, 29 anos, procurou o Serviço de Mastologia com relato de nódulo mamário à esquerda há oito dias, associado a dor local de leve intensidade. Ao exame notava-se hiperemia no quadrante inferior esquerdo, com nódulo de $5 \times 5 \mathrm{~cm}$, não aderido aos planos profundos, e um linfonodo de $1,5 \times 1,0 \mathrm{~cm}$, móvel, indolor na região axilar esquerda. A paciente não tinha antecedentes patológicos mórbidos. Era gesta 3, para 1,2 abortos e amamen- 
tou por 2 anos até há um mês. A mamografia mostrou mamas hiperdensas e calcificações pleomórficas disformes na junção dos quadrantes internos da mama esquerda e calcificações amorfas retroareolares na mama esquerda. Foram retirados 4 fragmentos da região acometida e o histopatológico mostrou fibrose extensa, acúmulo de secreção com células linfogranulocitárias e histiócitos, espessamento de vasos e ausência de neoplasia. Após duas semanas a paciente retornou queixando-se de drenagem purulenta local, sendo iniciada cefalexina, sem melhora evidente após 14 dias, e surgimento de processo fistular satélite. A secreção obtida foi negativa para BAAR, tanto na bacterioscopia quanto na cultura, e o PPD foi não reator. Iniciamos então empiricamente esquema antituberculostático com rifampicina, isoniazida e pirazinamida, com resposta clínica excelente. Durante o seguimento de um ano não foram encontrados outros focos de tuberculose, mantendo-se assintomática até o momento.

Caso 2 - Paciente do sexo feminino, 45 anos, procurou o mastologista com história de tumoração na mama direita desde há dois meses, com drenagem purulenta local, sem dor associada ou sintomas sistêmicos. Ao exame notava-se um nódulo de $6,5 \times 3,5 \mathrm{~cm}$ no quadrante inferior externo da mama direita, com área local ulcerada e drenagem de secreção mucopurulenta. Não havia adenopatia axilar. Paciente era gesta 9, para 9, sem nenhum aborto. Não usava contraceptivo oral e havia relato de abscesso na mama direita aos 14 anos. A ultra-sonografia mamária mostrava substituição fibroadiposa e espessamento do tecido subcutâneo da mama direita de contornos mal definidos. A mamografia mostrou hiperdensidade assimétrica ocupando praticamente toda a mama direita, com adenopatia axilar. A análise histopatológica realizada em 9 fragmentos mostrou neoformação vascular, acentuada exsudação mista, histiócitos e células gigantes multinucleadas de corpo estranho, com ausência de malignidade. A paciente apresentou piora da lesão, com surgimento rápido de várias lesões fistulosas na mama $\mathrm{D}$ associadas a edema, eritema e dor local (Figuras 1 e 2). A radiografia de tórax era normal e o PPD foi reator fraco. A análise da secreção foi negativa para BAAR, bem como a cultura; foi iniciada então terapia empírica com rifampicina, isoniazida e pirazinamida, com rápida melhora clínica e involução das lesões no período de 6 meses. Foi acompanhada ambulatorialmente durante 1 ano, não sendo observados outros focos da doença através de exame físico e complementar.

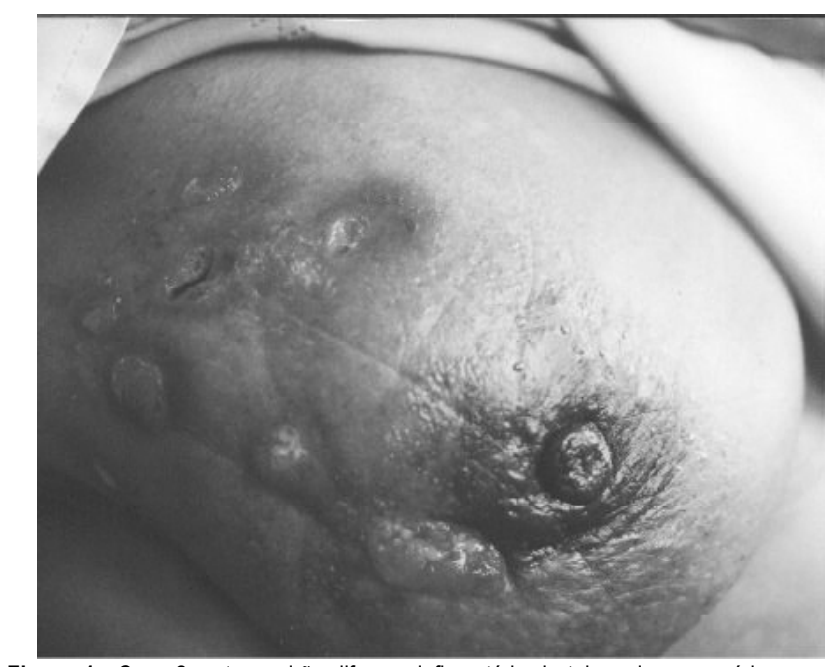

Figura 1 - Caso 2, notar padrão difuso e inflamatório da tuberculose mamária.

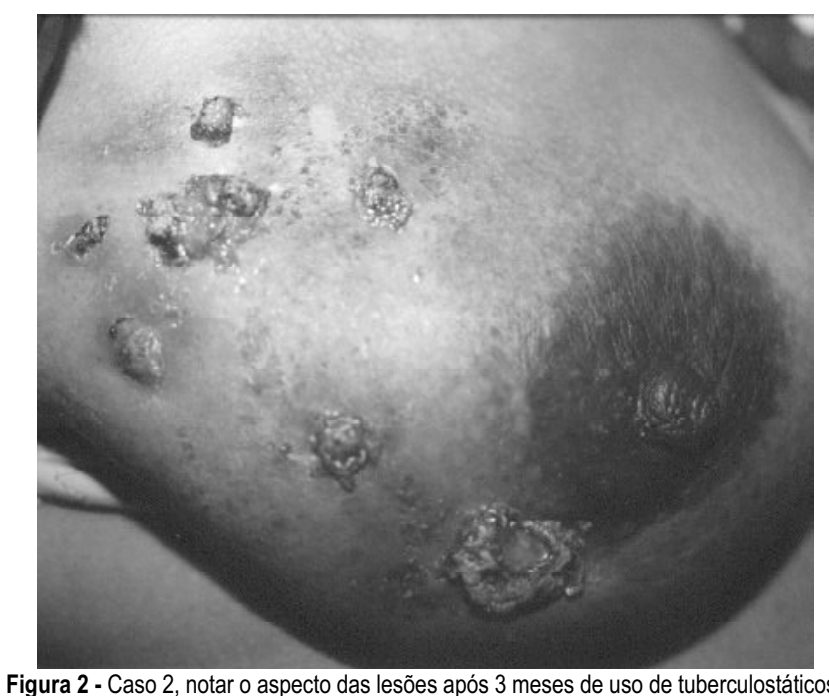

Caso 3 -Paciente do sexo feminino, 48 anos, com relato de nódulo na mama direita, doloroso, há 2 meses. Ao exame foram observados pequenos nódulos com diâmetro em torno de $1,5 \mathrm{~cm}$ na mama direita, localizados no quadrante superior interno. A paciente referia 2 gestações, negava abortos e informava apenas enxaqueca ocasional. A ultra-sonografia mostrava cinco nódulos sólidos, sem adenopatia axilar (Figura 3). A mamografia mostrou mamas heterogêneas com tecido fibroglandular assimétrico e desorganizado. O PPD era de $3 \mathrm{~mm}$ e o radiografia de tórax foi normal. Foi então realizada punção-biópsia, cujo laudo mostrou infiltrado inflamatório linfohistiocitário rico em plasmócitos, com focos de exsudação neutrofilica e células gigantes multinucleadas de corpo estranho e presença de bacilos corados pelo Ziehl-Neelsen, com ausência de malignidade. Foi iniciado então esquema tuberculostático, com boa resposta clínica e involução da lesão. Tem se mantido assintomática sem outras queixas clínicas durante o seguimento de 1 ano. 


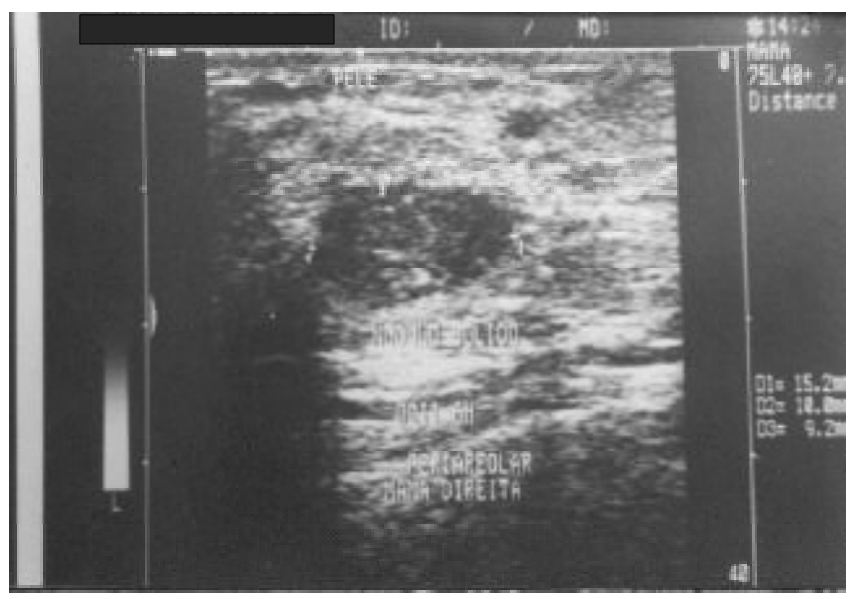

Figura 3 - Caso 3, notar o padrão nodular da tuberculose mamária à ultra-sonografia.

\section{Discussão}

Descrita no início do século XIX, a tuberculose mamária persiste como doença rara até os dias de hoje, variando em incidência de menos de $1 \%$ em países desenvolvidos até 3-5\% das patologias mamárias em países subdesenvolvidos como a Índia ${ }^{4}$. É basicamente dividida em primária e secundária, sendo a primeira forma definida quando não se identifica outro sítio de infecção pelo Mycobacterium tuberculosis, e é causada por inoculação direta no tecido mamário ${ }^{5}$. A forma secundária resulta da disseminação do bacilo de outros locais para o tecido mamário, por via linfática, hematogênica ou por contigüidade, sendo a via linfática a mais comum. O tecido mamário parece ser de certa forma resistente ao bacilo da tuberculose, como relatado por Webster em 1939 ao realizar 34 necrópsias em pacientes com tuberculose miliar, sendo a mama o único órgão não afetado $^{6}$. A lactação parece favorecer a infecção, já que a mama lactante é mais vascularizada ${ }^{6}$; a paciente do caso 1 havia amamentando por 2 anos, tendo-a suspendido um mês antes do início dos sintomas.

A tuberculose mamária acomete comumente mulheres entre 20-40 anos, geralmente com envolvimento unilateral das mamas; Mendes et al. ${ }^{5}$ descreveram recentemente um caso em um homem HIV positivo.

Em 1982, Hamit e Ragsdale ${ }^{7}$ classificaram a tuberculose mamária quanto à sua apresentação clínica em nodular, inflamatória disseminada (difusa) e esclerosante. A forma nodular, mais comum, começa como massa indolor de crescimento lento com ou sem envolvimento axilar e que progride para envolvimento cutâneo e formação de úlceras com seios de drenagem. Al-Marri et al. ${ }^{8}$ relatam a forma nodular como a mais fre- qüente encontrada entre as pacientes do seu trabalho. A forma difusa caracteriza-se por múltiplos focos de drenagem, com importante processo inflamatório. Já a forma esclerosante, menos comum, ocorre em mulheres idosas e apresenta maior grau de fibrose, com pouca supuração ou caseação, vendo-se na mamografia uma massa homogênea densa com septo fibroso e retração mamilar ${ }^{9}$.

A tuberculose mamária se apresenta como nódulos dolorosos ou não, edema e abaulamento mamário, espessamento cutâneo, retração do mamilo, úlceras com seios de drenagem. O diagnóstico é feito por análise microbiológica por pesquisa direta (bacterioscopia) e cultura do material ou análise histopatológica. A positividade da bacterioscopia é muito baixa: Shinde et al. ${ }^{9}$ obtiveram $12 \%$ e Gupta et al. ${ }^{10} 22,7 \%$ em suas descrições. A cultura tem positividade também baixa, menor que $50 \%{ }^{4,11}$. A biópsia pode demonstrar o bacilo pela coloração de Wade mas também tem baixa positividade, e o que encontramos no tecido é processo inflamatório granulomatoso com ou sem necrose caseosa. A mamografia mostra tecido hiperdenso, espessamento trabecular sugestivo de mastite, além de retração do mamilo, espessamento da pele e redução da mama segundo Makanjuola et al. ${ }^{11}$, numa análise de 1152 mamografias com 6 casos de tuberculose mamária ${ }^{11,12}$.

O tratamento é feito com tuberculostáticos, geralmente em esquemas de seis meses, sendo às vezes necessária abordagem cirúrgica com drenagem ou mesmo mastectomia; Shinde et al. ${ }^{9}$, em sua revisão relatam que $10 \%$ dos casos necessitaram de mastectomia simples por ausência de resposta à terapia, mas eram lesões grandes e de duração prolongada.

O diagnóstico diferencial de tuberculose mamária passa principalmente pelo carcinoma de mama nas suas formas nodular e inflamatória ${ }^{13}$. Entram no diagnóstico também: abscesso mamário, necrose gordurosa, mastite de células plasmocitárias, actinomicose e infecções fúngicas. Os nossos três casos mostram mulheres com faixa etária entre 29 e 48 anos com uma média de 40,6 anos, sem relato de contato com tuberculose ou doenças de base, que apresentaram envolvimento mamário por Mycobacterium tuberculosis, sendo que só obtivemos positividade microbiológica na paciente do caso 3 . Morsad et al. ${ }^{14}$ relataram série de 14 casos de tuberculose mamária em que o bacilo de Koch foi isolado também em apenas um caso. As pacientes dos casos 1 e 2, como tinham análise histopatológica sugestiva, com padrão granulomatoso e ausência de malignidade, foram sido tratadas empiricamente, com excelente resposta clínica (Figura 4). A baixa positividade na 
avaliação microbiológica é corroborada pelos achados na literatura. Em relação à apresentação clínica, as pacientes dos casos 1 e 2, com lesões cutâneas difusas associadas com drenagem purulenta, apresentaram o padrão difuso ou inflamatório disseminado. Já a paciente do caso 3, com sua forma mais localizada e sem envolvimento fistular, corresponde ao padrão nodular.

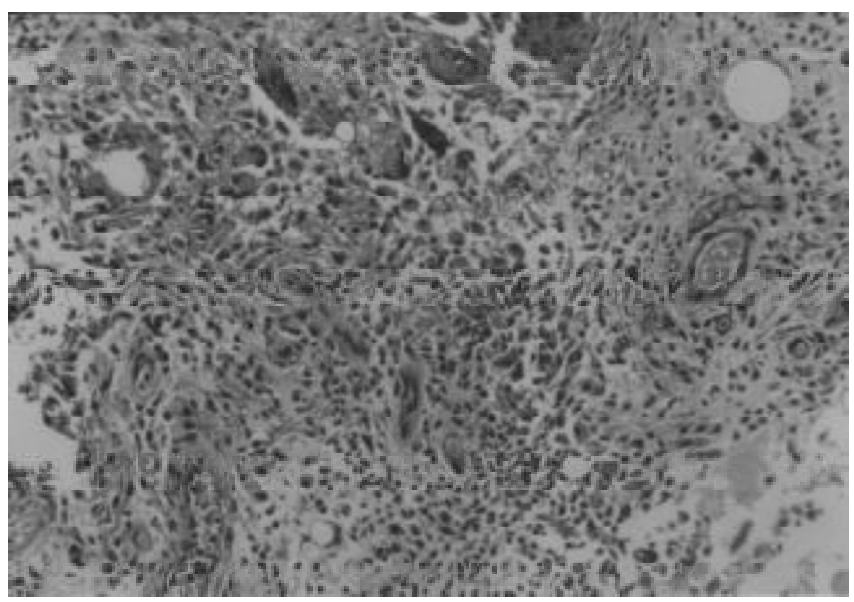

Figura 4 - Caso 2, padrão histológico (células gigantes multinucleadas de corpo estranho) da tuberculose mamária.

Em resumo, a tuberculose mamária ainda pode ser considerada uma doença rara nos dias de hoje, mas deve ser sempre lembrada quando nos depararmos com pacientes com envolvimento mamário de evolução subaguda, com nódulos ou processo inflamatório com presença de fistulas e que não apresentem indícios de malignidade no histopatológico, principalmente em países subdesenvolvidos.

\section{ABSTRACT}

Purpose: to make a differential diagnosis in regard to breast carcinoma and to evaluate diagnostic and clinical methods in the treatment of breast tuberculosis and the follow-up after adequate treatment.

Patients and Methods: three patients with breast tuberculosis were observed from March 2001 to March 2002; the first two were hospitalized at our Mastology Department and the third patient was treated at a private clinic. The clinical signs and symptoms, laboratory findings, response to therapy and follow-up were evaluated.

Results: the average age of the patients was 40.6 years. The most frequent signs and symptoms were pain and breast tumor. In two patients the presumptive diagnosis was based on the clinical findings, on the histological findings (granulomatous inflammatory process), and on the therapeutic response to tuberculostatic drugs. Only one patient had a microbiological diagnosis, as Koch's bacillus was identified in a sample of her breast tissue. Treatment with a triple tuberculostatic regimen, including rifampin, isoniazid and pyrazinamide, led to the regression of the lesions.

Conclusion: primary breast tuberculosis, a rare occurrence which may present clinically as a breast nodule and radiologically as carcinoma, should be taken into account when making the differential diagnosis of patients presenting with mammary mass.

KEY WORDS: Breast. Tuberculosis. Granulomatous inflammation.

\section{Referências}

1. Barros ACSD, Silva HMS, Dias EN. Mastologia: condutas. $1^{\text {a }}$ ed. Rio de Janeiro: Revinter; 1999. Tuberculose mamária; p.62-5.

2. Abboud P, Bancheri F, Bajolet-Laudinat O, Beguinot I, Wahl P, Quereux C. Tuberculose mammaire. A propos d'un cas à forme inflammatoire diffuse. J Gynecol Obstet Biol Reprod (Paris) 1997; 26:822-4.

3. O'Reilly M, Patel KR, Cummins R. Tuberculosis of the breast presenting as carcinoma. Mil Med 2000; 165:800-2.

4. Goksoy E, Duren M, Durgun V, Uygun N. Tuberculosis of the breast. Eur J Surg 1995; 161:4713.

5. Mendes WS, Levi M, Levi GC. Tuberculose mamária: relato de caso e revisão de literatura. Rev Hosp Clín Fac Med São Paulo 1996; 51:136-7.

6. Yilmaz F, Yagmur Y, Uzunlar AK. Tuberculosis in an intramammary lymph node. Eur J Surg 2000; 166:267-8.

7. Hamit HF, Ragsdale TH. Mamary tuberculosis. J R Soc Med 1982; 75:764-5.

8. Al-Marri MR, Almosleh A, Almoslmani Y. Primary tuberculosis of the breast in Qatar: ten-year experience and review of the literature. Eur J Surg 2000; 166:687-90.

9. Shinde SR, Chandawarkar RY, Deshmukh SP. Tuberculosis of the breast masquerading as carcinoma: a study of 100 patients. World J Surg 1995; 19:379-81.

10.Gupta D, Rajwanshi A, Gupta SK, Nijhawan R, Saran RK, Singh R. Fine needle aspiration cytology in the diagnosis of tuberculous mastitis. Acta Cytol 1999; 43:191-4. 
11.Makanjuola D, Murshid K, Al Sulaimani S, Al Saleh M. Mammographic features of breast tuberculosis: the skin bulge and sinus tract sign. Clin Radiol 1996; $51: 354-8$.

12.Zandrino F, Monetti F, Gandolfo N. Primary tuberculosis of the breast. A case report. Acta Radiol 2000;41:61-3.
13.Wong Chen FJ, Robles Gonzalez D, Berreto Redas O, Guzman Patraca C. Tuberculosis mamária: presentación de un caso y revisión de la literatura. Ginecol Obstet Méx 1997; 65:92-5.

14. Morsad F, Ghazli M, Boumzgou K, et al. Tuberculose mammaire. J Gynecol Obstet Biol Reprod (Paris) 2001;30:331-7. 